\title{
Computerized Neurocognitive Test (CNT) in mild cognitive impairment and Alzheimer's disease
}

\author{
Maira Okada de Oliveira, Sonia Maria Dozzi Brucki
}

\begin{abstract}
Currently, computerized batteries are of great value in detecting cognitive impairment. This aim of this review was to compare the computerized neurocognitive batteries used in most studies with cognitive decline over the last 10 years. Using the search words computerized cognitive assessment with: dementia, mild cognitive impairment, and Alzheimer's disease, the CogState, CNS Vital Sings, COGDRAS and Mindstreams batteries were retrieved.

Key words: computerized neurocognitive tests, computerized neuropsychological tests, Alzheimer's disease, mild cognitive impairment, elderly, cognition.
\end{abstract}

\section{TESTES NEUROCOGNITIVOS COMPUTADORIZADOS NO COMPROMETIMENTO COGNITIVO LEVE E DOENÇA DE ALZHEIMER}

RESUMO. Atualmente, baterias de testes computadorizados têm sido de grande valor na detecção de comprometimento cognitivo. Esta revisão teve como objetivo comparar as baterias cognitivas computadorizadas que foram utilizadas nos últimos 10 anos, na maioria dos estudos com declínio cognitivo. Usando as palavras avaliação cognitiva computadorizada com: demência, comprometimento cognitivo leve e doença de Alzheimer nós encontramos as baterias CogState, CNS Vital Signs, COGDRAS e Mindstreams.

Palavras-chave: testes neurocognitivos computadorizados, testes neuropsicológicos computadorizados, doença de Alzheimer, comprometimento cognitivo leve, idosos, cognição.

\section{INTRODUCTION}

The use of Computerized neurocognitive been widely studied and may be the most suitable tool for the early detection of impairments. ${ }^{1} \mathrm{CNT}$ are able to measure mild degrees of cognitive impairment and can gauge the effectiveness of an intervention. ${ }^{2}$ Computerized batteries offer a number of advantages over paper-and-pencil type tests: they are precise, accurate and can be timed to the nearest millisecond. In addition they are easy to administer and score, have greater standardization and multiple parallel versions may also be available, known to reduce practice effects. $^{3}$

The advantages of a computerized battery are that it can be applied at bedside using a tablet device, results can be instant, and the tests applied by any person, eliminating exam- iner effects and providing increased reliability. The battery is also language independent and can be used in patients with mild aphasia offering consistent administration and scoring, while computerized tests can also generate alternative forms for repeated testing. ${ }^{2,4,5}$

The disadvantages include the absence of the active participation of consulting neuropsychologists analyzing the qualitative performance, and that the limitations in the ability to understand and manipulate information technology can cause a negative effect because elderly tend not to be familiar with it. ${ }^{2,6}$

The aim of this review was to compare the features of the computerized neuropsychological batteries used in most studies involving the cognitively impaired over the last 10 years, in order to verify which are most suitable for use in clinical practice within an outpatient clinic.

Cognitive Neurology and Behavioral Group of the Department of Neurology of the University of São Paulo, SP, Brazil.

Sonia Maria Dozzi Brucki. Rua Rio Grande, 180/61 - 04018-000 São Paulo SP - Brazil. E-mail: sbrucki@uol.com.br

Disclosure: The authors report no conflicts of interest.

Received November 12, 2013. Accepted in final form January 26, 2014. 


\section{METHODS}

We examined on-line articles published between 2004 and 2014 on the PubMed database or the references of these articles, which cited mainly reliability and validity studies prior to 2004, searching for the most used and most cited battery for dementia, Alzheimer's disease (AD) and Mild Cognitive Impairment (MCI). The descriptors computerized cognitive assessment with: dementia, mild cognitive impairment and Alzheimer's disease were used. Only studies available in English were included.

Exclusion criteria. Articles published before 2004, those addressing other dementias or computer programs used for rehabilitation, were excluded as were articles unavailable online.

\section{RESULTS}

A total of 101 articles published between 2004 and 2014 were identified. Sixty-one articles were excluded for not assessing patients with $\mathrm{AD}$ and $\mathrm{MCI}$ or because the computerized test was cited only once. Some articles appeared more than once. Articles were divided by tests, population, mean age, diagnosis and main results (Table 1) and organized according to the main characteristics of the tests (Table 2).

CogState. ${ }^{7}$ Cogstate Research is a repeatable and sensitive computerized cognitive testing system designed specifically for use in research studies and can evaluate patients aged 6 to 106, which includes: attention deficit hyperactivity disorder (ADHD), fatigue and drug effects, post-operative cognitive dysfunction, MCI, early Alzheimer's disease and dementia, Schizophrenia and mood disorders. CogState was developed as a dementia screening instrument and for assessing concussion and has been shown to be valid, reliable, and sensitive for detecting cognitive impairment., ${ }^{7,8}$ Subtests include measures of simple selection and complex reaction times, continuous monitoring, working memory, matching, incidental learning, and associative learning. The subtests are based on playing card formats and written instructions are presented on screen. Responses are made via a computer keyboard represented graphically on the screen, with responses using the "k" key for yes and " $\mathrm{d}$ " key for no. The battery requires 15 to 20 minutes to complete. ${ }^{1}$ Specialized tasks can assess attention, memory, executive function, as well as language and socialemotional cognition if required. In addition to research studies, the batteries of tasks are used in commercial trials to determine the effect of drugs. Minimal learning effects ensure that participants can be tested repeatedly as often as needed, even multiple times in short periods (over a single day). ${ }^{7,10}$

In a study that evaluated healthy older adults ( $n=105)$, amnestic MCI $(n=48)$ and $A D(n=42)$ patients over three months, the CogState battery showed high test-retest reliability and stability in all groups and was able to detect $\mathrm{AD}$-related cognitive impairment. ${ }^{9}$

Another study showed that in established dementia, the CogState tasks appeared to be sensitive for detecting cognitive impairment. Repeat administration also provided acceptable stability and test-retest reliability with minimal practice effects at short test-retest intervals even on the same day. ${ }^{10} \mathrm{~A}$ study comparing dementia (AD, frontotemporal dementia, and dementia with Lewy bodies), MCI, and healthy controls, found the CogState was able to successfully differentiate dementia patients from control subjects, but achieved minimal differentiation between controls and MCI. Repeat administration also provided acceptable stability and testretest reliability with minimal practice effects at short test-retest intervals. ${ }^{11}$ In a study following healthy older adults over a one-year period, CogState proved to be an instrument that can be used repetitively (at 3, 6, 9 and 12 months), differentiating individuals with risk of increased rates of cognitive decline in memory. ${ }^{12}$

CNS Vital Signs (VS). ${ }^{13}$ Developed as a brief clinical evaluation tool, its tests are familiar and well-established: verbal and visual memory, finger tapping, symbol digit coding, Stroop Test, a test of shifting attention and the continuous performance test. Gualtieri and Johnson ${ }^{13}$ published a study of reliability and validity among 1069 individuals aged 7-90 years with psychometric characteristics. The reliability of the tests in the CNSVS battery are very similar to the characteristics of the conventional neuropsychological tests, and the battery was sensitive for detecting the most common causes of cognitive impairment, but should be used as a screening instrument and not as a substitute for formal neuropsychological testing. ${ }^{13,14}$

Cognitive Drug Research Computerized Assessment System (COGDRAS). ${ }^{15}$ COGDRAS was developed for use in neuropharmacological research. ${ }^{15}$ A study with 152 older adults that investigated a combination of tests for the diagnosis of dementia using conventional tests and subtests of two computerized battery: the Poon-Baro-Wens (PBW) battery ${ }^{16}$ and COGDRAS, found that computerized tests added very little diagnostic value. ${ }^{17}$

This battery is widely used in clinical trials testing 


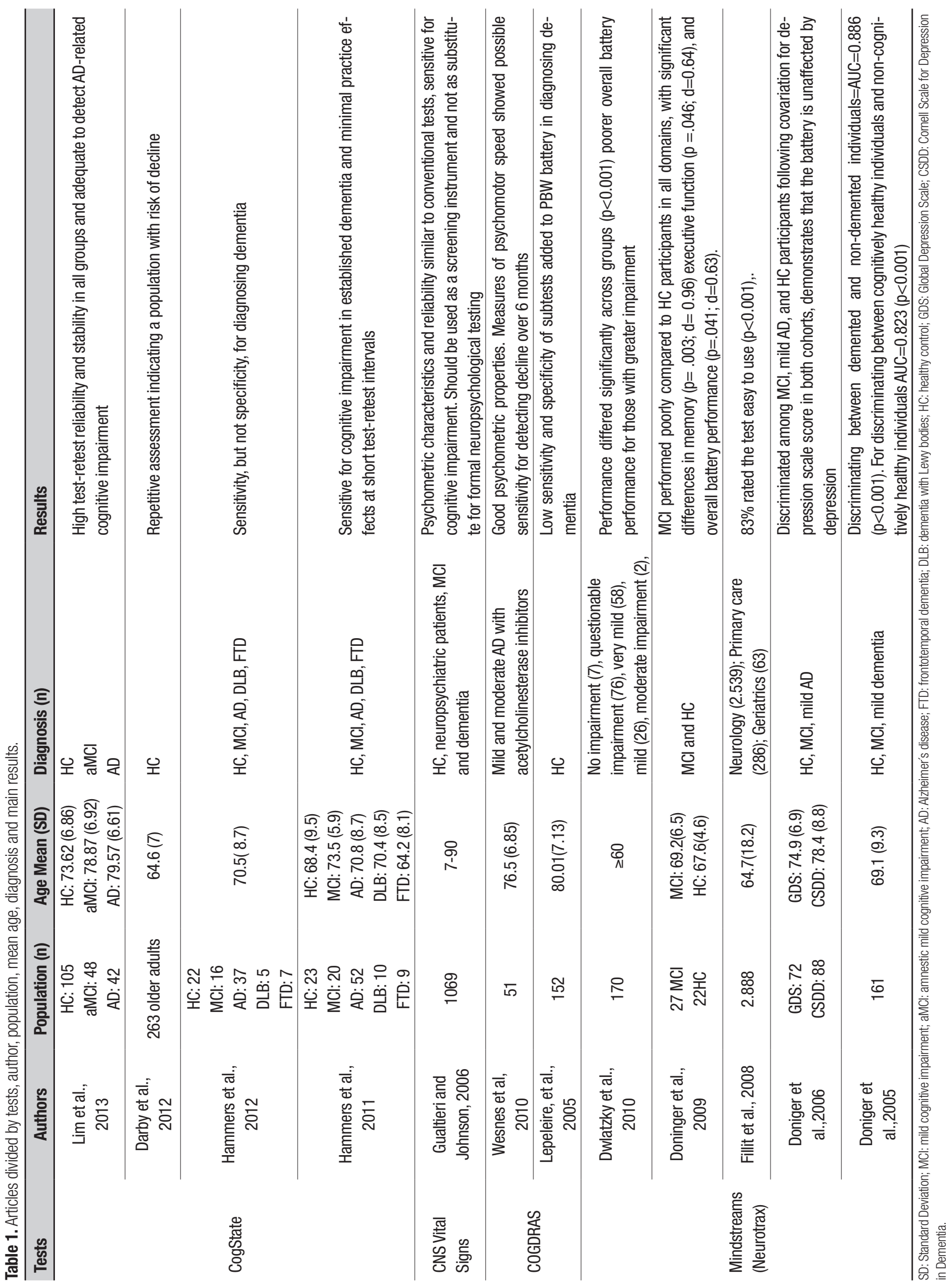


Table 2. Main characteristics of the computerized tests.

\begin{tabular}{|c|c|c|c|c|c|}
\hline Test & Created & Screening for & Domains & Time & Site \\
\hline CogState & 2001 & $\begin{array}{l}\text { MCl, early Alzheimer's } \\
\text { disease and dementia }\end{array}$ & $\begin{array}{l}\text { Attention, memory, executive function, language, so- } \\
\text { cial cognition }\end{array}$ & $15-20$ minutes & www.cogstate.com \\
\hline CNS Vital Signs & 2002 & $\mathrm{MCl}$ & $\begin{array}{l}\text { Memory, attention, psychomotor speed, processing } \\
\text { speed, cognitive flexibility }\end{array}$ & 30 minutes & https://www.cnsvs.com \\
\hline COGDRAS & & $\mathrm{AD}$ and dementias & $\begin{array}{l}\text { Attention, concentration, verbal and visuo-spatial re- } \\
\text { call and recognition, verbal and visuo-spatial working } \\
\text { memory, psychomotor speed and information pro- } \\
\text { cessing speed }\end{array}$ & 30 minutes & \\
\hline $\begin{array}{l}\text { Mindstreams } \\
\text { (Neurotrax) }\end{array}$ & 2000 & $\mathrm{MCl}$ & $\begin{array}{l}\text { Memory, executive function, visuospatial, verbal flu- } \\
\text { ency, attention, motor skills, information processing }\end{array}$ & 45-60 minutes & www.neurotrax.com \\
\hline
\end{tabular}

MCl: Mild Cognitive Impairment; AD: Alzheimer's disease

the effect of drugs, mainly on attention. ${ }^{18} \mathrm{~A}$ study with $51 \mathrm{AD}$ patients assessing the COGDRAS during treatment with acetylcholinesterase inhibitors found this battery has good psychometric properties while the measures of psychomotor speed showed possible sensitivity for detecting decline over 6 months. ${ }^{19}$

Mindstreams (Neurotrax). ${ }^{20} \mathrm{~A}$ computerized testing system for comprehensive clinical assessment of cognitive impairment, designed primarily for use in the elderly. The battery consists of nine subtests: verbal memory, nonverbal memory, Go-No Go response inhibition, Stroop interference, problem solving, visual spatial imagery, verbal rhyming, verbal naming, staged information processing speed, finger tapping, and visuomotor planning. ${ }^{1}$ A study showed the capacity of this battery to discriminate individuals with $\mathrm{MCI}$ from cognitively healthy elderly. ${ }^{20}$ Another study by the same author found that the Mindstreams battery provided detailed and distinct cognitive profiles of patients with moderate impairment. ${ }^{21}$

In a study assessing 2888 patients, $83 \%$ rated the test as easy-to-use and patients were divided into nonusers of computers, patients older than 75 , and poor performers. ${ }^{22}$

In a study with a population of 161 older adults divided into healthy, MCI and mild dementia, the Mindstreams was able to discriminate between demented and non-demented individuals $=\mathrm{AUC}=0.886(\mathrm{p}<0.001)$ and between cognitively healthy individuals and noncognitively healthy individuals AUC $=0.823(\mathrm{p}<0.001) .{ }^{22}$

In another study, patients were divided into two groups, one assessed by the Global Depression Scale (GDS) ${ }^{23}$ and another by the Cornell Scale for Depression in Dementia (CSDD). ${ }^{24}$ Mindstreams discriminated among $\mathrm{MCI}$, mild $\mathrm{AD}$, and healthy control $(\mathrm{HC})$ partici- pants following covariation for depression scale score in both cohorts, demonstrating that this battery is unaffected by depression. ${ }^{25}$

A study was performed in Afro-Americans, comprising $27 \mathrm{MCI}$ and $22 \mathrm{HC}$ subjects. The MCI patients performed poorly compared to HC participants in all domains, with significant differences in memory ( $\mathrm{p}=.003$; $\mathrm{d}=0.96)$, executive function ( $\mathrm{p}=.046 ; \mathrm{d}=0.64)$, and overall battery performance $(\mathrm{p}=.041 ; \mathrm{d}=0.63){ }^{26}$

The Mindstreams battery was used in a study as a gold standard for a validation of the Hebrew version of the Montreal Cognitive Assessment (MoCA Test) as a screening instrument for the early detection of $\mathrm{MCI}{ }^{27,28}$

\section{DISCUSSION}

Some batteries are good for measuring reaction time (CODGRAS) or detecting AD (CogState), while others are for screening (CNS VS) and are easy-to-use and effective for discriminating between healthy controls, $\mathrm{MCI}$ and $\mathrm{AD}$ (Mindstreams).

Slow reaction time and memory impairment seem to be the main features of cognitive impairment, especially in $\mathrm{AD}$, and clinical markers should be taken into account in the choice of test. ${ }^{30}$

A review article about advances in design for $A D$ in clinical trials compared the most widely used tests, namely, Automated Neuropsychological Assessment Metrics (ANAM), ${ }^{31}$ Computer Assessment of Mild Cognitive Impairment (CAMCI), ${ }^{32}$ CANS-MCI, ${ }^{33}$ CANTAB, ${ }^{34,35}$ CNSVS, Cognitive Drug Research (CDR/COGDRAS), CogState, Cognitive Skills Index (CSI), ${ }^{36} \mathrm{Mi}-$ croCog and Mindstreams (Neurotrax). Strengths and weaknesses were detected for all tests, but the authors were emphatic in affirming that computerized assessment offers several advantages over pen-and-paper tests, in that they have a high degree of standardization 
in administration and scoring and can measure reaction time accurately. ${ }^{37}$

It is important to highlight the role of the physician or neuropsychologist in cognitive assessment, noting that the computerized test should be considered one more tool to have on hand and not the sole means of reaching the diagnosis.
In conclusion, all CNTs analyzed seemed to be suitable for use in clinical practice. The choice of battery depends on the aspects the clinician wishes to assess, the cost of equipment, and time available. Finally, battery choice also depends on the availability of a version in the language of the subjects studied.

\section{REFERENCES}

1. Wild K, Howieson D, Webbe F, Seelye A, KayenJ. Status of computerized cognitive testing in aging: A systematic review. Alzheimers Dement 2008; 4: 428-437.

2. Gualtieri CT, Johson LG. Reability and validity of a computerized neurocognitive test battery, CNS Vital Signs. Arch Clin Neuropsychol 2006;21:623-643.

3. Silverberg NB, Ryan LM, Carrillo MC et al. Assessment of cognition in early dementia. Alzheimers Dement 2011;7:e60-e76.

4. Elwood RW. MicroCog: assessment of cognitive functioning. Neuropsychol Rev 2001;11: 89-100.

5. Égerházi A, Berecz R, BartókE, Degrell I. Automated Neuropsychological Test Battery (CANTAB) in mild cognitive impairment and in Alzheimer's disease. Prog Neuropsychopharmacol Biol Psychiatry 2007;31:746-751.

6. Martin TA. Ethical challenges with the use of information technology and telecommunications in neuropsychology. In: Bush S. A casebook of ethical challenges in neuropsychology. London and New York: Taylor \& Francis, 2005.

7. CogState. The global leader in assessing, monitoring and improving cognition. Acessed on: http://cogstate.com/academic/\#.Uvef32JdWSo

8. Gualtieri T, Computerized Neurocognitive Testing and its Potential for Modern Psychiatry. Psychiatry (Edgmont). 2004;1:29-36.

9. Lim YY, Jaeger J, Harrington K, et al. Three-Month Stability of the CogState Brief Battery in Healthy Older Adults, Mild Cognitive Impairment, and Alzheimer's Disease: Results from the Australian Imaging, Biomarkers, and Lifestyle-Rate of Change Substudy (AIBL-ROCS). Arch Clin Neuropsychol. 2013;28:320-330.

10. Hammers D, Spurgeon E, Ryan K, et al. Reliability of Repeated Cognitive Assessment of Dementia Using a Brief Computerized Battery. Am J Alzheimers Dis Other Demen. 2011;26:326-333.

11. Hammers D, Spurgeon E, Ryan K, el al. Validity of a Brief Computerized Cognitive Screening Test in Dementia. J Geriatr Psychiatry Neurol 2012;25:89-99.

12. Darby DG, Pietrzak RH, Fredrickson J. Intraindividual cognitive decline using a brief computerized cognitive screening test. Alzheimers Dement. 2012;8:95-104

13. Gualtieri CT, Johnson LG. Neurocognitive testing supports a broader concept of mild cognitive impairment. Am J Alzheimers Dis Other Demen 2005;20:359-366.

14. Gualtieri CT, Johnson LG. Reliability and validity of a computerized neurocognitive test battery, CNS Vital Signs. Arch Clin Neuropsychol 2006;21:623- 43

15. Simpson PM, Surmon DJ, Wesnes KA, Wilcock GK. The Cognitive Drug Research Computerized Assessment System for demented patients: a validation study. Int J Geriatr Soc 1991;6:95-102.

16. Wens L. Impliciet en expliciet geheugen bij dementie van het Alzheimertype. Faculteit Psychologische en Pedagogische Wetenschappen, Katholieke Universiteit Leuven, 1993.

17. De Lepeleire J, Heyrman J, Baro F, Buntinx F. A combination of tests for the diagnosis of dementia had a significant diagnostic value. J Clin Epidemiol 2005;58:217-225.

18. Galvin JE, Cornblatt B, Newhouse P, et al. Effects of galantamine on measures of attention: results from 2 clinical trials in Alzheimer disease patients with comparisons to donepezil. Alzheimer Dis Assoc Disord 2008;22:30-38

19. Wesnes K, Edgar C, Andreasen N, et al. Computerized cognition assessment during acetylcholinesterase inhibitor treatment in Alzheimer's disease. Acta Neurol Scand 2010;122:270-277.
20. Dwolatzky T, Whitehead V, Doniger GM et al. Validity of a novel computerized cognitive battery for mild cognitive impairment. BMC Geriatrics 2003,3:4.

21. Dwolatzky T, Dimant L, Simon ES, Doniger GM. Validity of a short computerized assessment battery for moderate cognitive impairment and dementia. Int Psychogeriatr 2010;22:795-803.

22. Fillit HM, Simon ES, Doniger GM, Cummings JL. Practicality of a computerized system for cognitive assessment in the elderly. Alzheimers Dement 2008;4:14-21

23. Yesavage JA, Brink TL, Rose TL, et al.: Development and validation of a geriatric depression screening scale: A preliminary report. J Psychiatr Res 1982;17:37-49.

24. Alexopoulos GS, Abrams RC, Young RC, et al. Cornell Scale for Depression in Dementia. Biol Psychiatry 1988;23:271-284.

25. Doniger GM, Dwolatzky T, Zucker DM, Chertkow H, Crystal H, Schweiger A, Simon ES. Computerized cognitive testing battery identifies mild cognitive impairment and mild dementia even in the presence of depressive symptoms. Am J Alzheimers Dis Other Demen 2006;21: 28-36.

26. Doniger GM, Zucker DM, Schweiger A, et al. Towards practical cognitive assessment for detection of early dementia: a 30-minute computerized battery discriminates as well as longer testing. Curr Alzheimer Res 2005;2:117-124.

27. Doniger GM, Jo MY, Simon ES, Crystal HA. Computerized cognitive assessment of mild cognitive impairment in urban African Americans. Am J Alzheimers Dis Other Demen 2009;24:396-403.

28. Nasreddine ZS, Phillips NA, Bedirian V, et al. The Montreal Cognitive Assessment, MoCA: a brief screening tool for mild cognitive impairment. J Am Geriatr Soc 2005;53:695-699.

29. Lifshitz M, Dwolatzky T, Press Y. Validation of the Hebrew version of the MoCA test as a screening instrument for the early detection of mildcognitive impairment in elderly individuals. J Geriatr Psychiatry Neurol 2012;25:155-161.

30. Charchat H, Nitrini R, Caramelli P, Sameshima K. Investigação de marcadores clínicos dos estágios iniciais da doença de Alzheimer com testes neuropsicológicos computadorizados. Psicol Reflex Crít 2001;14:305-316.

31. Levinson D, Reeves D, Watson J, Harrison M. Automated neuropsychological assessment metrics (ANAM) measures of cognitive effects of Alzheimer's disease. Arch Clin Neuropsychol 2005;20:403-408.

32. Saxton J, Morrow L, Eschman A, Archer G, Luther J, Zuccolotto A. Computer assessment of mild cognitive impairment. Postgrad Med 2009;121:177-185.

33. Tornatore JB, Hill E, Laboff J, McGann ME. Selfadministered screening for mild cognitive impairment: Initial validation of a computerized test battery. J Neuropsychiatr Clin Neurosci 2005;17:98-105.

34. Fowler KS, Saling MM, Conway EL Semple JM, Louis WJ. Computerized neuropsychological tests in the early detection of dementia: prospective findings. J Int Neuropsychol Soc 1997;3:139-146.

35. De Jager CA, Milwain E, Budge M. Early detection of isolated memory deficits in the elderly: the need for more sensitive neuropsychological tests. Psychol Med 2002;32:483-491.

36. DeLepeliere J, Heyrman J, Baro F, Buntinx F. A combination of tests for the diagnosis of dementiahad a significant diagnostic value. J Clin Epidemiol 2005; 58: 217-225.

37. Cummings J, Gould H, Zhong K. Advances in designs for Alzheimer's disease clinical trials. Am J Neurodegener Dis 2012;1:205-216. 